\title{
Labyrinthe
}

32 | 2009 (1)

Le petit théâtre intellectuel

\section{Dieudonné ou le porte-parlure}

\section{Laurent Dubreuil}

\section{(2) OpenEdition}

\section{Journals}

Édition électronique

URL : http://journals.openedition.org/labyrinthe/3992

DOI : $10.4000 /$ labyrinthe.3992

ISSN : 1950-6031

Éditeur

Hermann

Édition imprimée

Date de publication : 19 juin 2009

Pagination : 67-68

ISBN : 978-2-7056-6885-3

Référence électronique

Laurent Dubreuil, «Dieudonné ou le porte-parlure », Labyrinthe [En ligne], 32 | 2009 (1), mis en ligne le 01

février 2011, consulté le 21 avril 2019. URL : http://journals.openedition.org/labyrinthe/3992 ; DOI :

10.4000/labyrinthe.3992

Propriété intellectuelle 


\section{ACTE II : PORTRAITS}

\section{DIEUDONNÉ OU LE PORTE-PARLURE}

Dieudonné est passé du show-biz au théâtre intellectuel quand il s'est affirmé noir, en combat contre la discrimination. Rendu vite Maître à penser d'une jeunesse (post)coloniale et banlieusarde, l'acteur a multiplié les rôles et les postures. Toujours Comique de profession quoique de moins en moins drôle, et à chaque spectacle enfoncé davantage dans un sérieux ressassement, Dieudonné s'affirme comme le Porte-parole de ceux qui ne veulent plus en avoir'. Il s'exprime en Témoin quand il revient d'un voyage en Algérie où il parle de la " pornographie mémorielle» ou du Cameroun avec Maman Le Pen. Ne doutez pas de son côté Pythie s'il place ses espoirs dans une jeunesse qu'il semble vouloir gouroutiser. Quant à son étrange et récent statut de compagnon de route du Front national (pour des raisons non politiques, c'est entendu), voilà qui nous produit un bel et parfait Renégat. Nous tenons une part du problème. Dieudonné est trop prisonnier de la morne structure du one-man-show. Il a compris qu'il pouvait entrer sur la scène intellectuelle; dès lors, il a cherché à endosser tous les rôles, quitte, en révélant la nature du répertoire, à perdre l'efficacité affichée par le penseur digne et professionnel.

Où qu'il soit désormais, Dieudonné enchaîne ainsi les sketches en permanence, il n'est plus que cette multiplicité de personnages possibles. Oui, Dieudonné c'est lui, lui l'anti-raciste patenté en 1997 et dont l'ennemi principal était l'extrême droite, lui le pro-palestinien ennemi du lobby sioniste dont Arthur ou Michel Drucker sont apparemment les puissants représentants, lui le pourfendeur des monothéismes, lui qui comprend le port du voile chez les musulmanes de France, lui qui passe au quartier général du FN à l'issue du premier tour de l'élection présidentielle en 2007, lui, etc. Il est tout cela, tour à tour, à la fois, peu importe; il y croit; il y fait croire. La cause individuelle de cette exagération, beaucoup la cherchent. Est-ce si nécessaire? Sans doute l'hypothèse d'un léger décollement du cerveau chez l'intéressé serait-elle suffisante. Mais bon,

1. Antoine Wave Garnier, dans « « 1905 », c’est notre indifférence qui va le tuer », énonce, en soutien à Dieudonné, « Nous avons trop été habitués à ce que d'autres parlent pour nous ou en notre nom. » (URL http://www.grioo.com/info4709.html; texte consulté le 10 janvier 2009). 
il est devenu fou ne va pas très loin. Surtout, Dieudonné continue de l'ouvrir', et, plus, de susciter, d'encourager un gigantesque babil. Non seulement les indignés, mais les hauts - et bas - parleurs auto-réputés, en particulier les Blogueurs, comme les Ogres ou « la banlieue s'exprime », un collectif plutôt philo-lepéniste cristallisé après les émeutes de 2005. Bien loin d'être le véritable pionnier de la parole noire ou indigène qu'il prétend incarner, Dieudonné sert toutefois d'Animateur à une polyphonie médiatique. Il orchestre pour partie un contradictoire brouhaha sur la France (post) coloniale, il est le producteur d'une émission d'idées simples sur le conflit israëlo-palestinien et ce qui y ressemble.

Pour en arriver là, Dieudonné se fait le rhapsode des phrases de comptoir, des pseudo-théories, des quatrièmes de couverture d'épais ouvrages, des élucubrations télévisuelles, des forfanteries politiques, des cris, des insultes, des dialogues de films à demi oubliés. Il devient le grand boulevard de la parlure extrémiste, de ce qu'il juge tel en tout cas, radical, « diabolisé », « infréquentable ». L'ennui d'ailleurs, pour un ennemi des pouvoirs institués, étant l'obligation de toujours accepter la logique de «l'établissement» dans l'espoir de choquer. Une fois que Dieudonné aura présenté son prochain spectacle en 2010 depuis la nouvelle grotte de Ben Laden, je crains qu'il ne doive dîner ensuite avec les cadavres de Mao et Staline s'il veut maintenir son ascension dans ce qu'il nomme l'insolence. À moins qu'il ne se rallie ex abrupto à George W. Bush dont il troublerait alors la somnolente retraite; on n'est pas à un revirement près tant qu'il y a de l'effet... Quel que soit l'avenir de ce projet de transgression mondaine, le sinistre Comique, tant qu'il en restera à ces cadres de pensée, est maintenant voué à répéter la banalité. Se concevant en marge de l'officielle information, il doit en adopter les valeurs - fût-ce en les inversant ou les neutralisant au cri soudain quasi menaçant de «Liberté d'expression! ». Dieudonné confond l'inaudible, le malentendu, le muet et le tu; pour le seul profit, in fine, du contrôle langagier. Il y a sûrement une originalité ici, qui consiste à dire presque tout et n'importe quoi. Et une trivialité, si paradoxalement représentative du pouvoir dominant, qui naît de l'entrechoc de phrases sans rapports autres que la cote, même négative, de leur spectaculaire locuteur. Ou comment à force Dieudonné est devenu le parangon de l'« intellectuel » porte-parlure.

L. D.

1. «Ferme-la » est devenu le gimmick apotropaïque de Dieudonné. 